\title{
Behavior of suspended particulate matter emitted from combustion of agricultural residue biomass under different temperatures
}

\author{
Q. Wang, S. Itoh, K. Itoh, P. Apaer, Q. Chen, D. Niida, \\ N. Mitsumura, S. Animesh, K. Sekiguchi \& T. Endo \\ Department of Environmental Science and Technology, \\ Graduate School of Science and Engineering, Saitama University, Japan
}

\begin{abstract}
There are large quantities of waste rice husk and straw estimated around 3.9 million tons as biomass waste every year in Japan. Air pollutants emitted from exhaust gases of rice husk incineration lead to environmental damage, not only because of the influence on global environment and climate, when released into the atmosphere, but also on human health due to local air pollution. Therefore, it is necessary to effectively utilize waste rice husk and straw to reduce air pollutants. In recent years, there has been an increasing demand on the utilization of unused biomass instead of fossil oil fuel in combustors for farminggreenhouses heating during the winter season. The increasing demand will increase the running costs. In general, since these combustors are small in size, there is a lack of regulations or laws (e.g. The Air Pollution Control Act and The Waste Disposal and Public Cleaning Law) in operation for their air pollution control. So far, small size combustors are characterized by their simplicity of structure and low costs. However, they emit visible black carbon (elemental carbon) due to their poor combustion performance.

In this study, we investigated that the possibility of the substitution of fossil fuel by waste rice husk and rice straw in laboratory model combustion experiments. We evaluated the emission behavior of harmful air pollutants emitted from rice husk and straw combustion by measuring carbonaceous and ionic composition of suspended particulate matter in the exhaust gases. From the analytical results we found that particulate mass concentrations reduced substantially at high temperature combustion. From the results of our study, it can be suggested that stable combustion performance under suitable conditions
\end{abstract}


in order to control less air pollutants emitted from biomass fuel although small size combustors are still not regulated.

Keywords: rice husk and rice straw, small size combustors, combustion conditions, carbonaceous, ionic and metallic composition, PM2.5.

\section{Introduction}

Global warming is become increasingly evident in the global climate. Combustion of fossil fuel is generally admitted as the main cause for global warming. Though, the use of fossil fuel is expected to increase in the future because of economic development and growth of population in developing countries (Saidur et al. [1]), hence, the only solution is zero-emission technology, that is, to reduce all possible emissions produced by human activities to zero (Li Dong et al. [2]). In order to achieve zero-emissions, it is important to apply a technology to utilize all unused biomass (Hansen et al. [3]; Ilipoulou et al. [4]).

Currently in Japan agriculture and forestry produce biomass residues from where a very small amount is used, and unused biomass is mostly being incinerated for disposal, due to its high cost of collection, transport, and storage and also the needs of energy that it implies. Moreover, the urgent countermeasures are required to reduce the air pollution from illegal waste biomass incineration. It is estimated that only in Japan around 3.9 million tons of waste rice husk and rice straw, which is the most common agricultural residue in the country, are wasted every year. Additionally, since rice is the staple food and regular part of the diet for almost half of the world population, an effective utilization of waste rice husk and straw as biomass fuel would be an important countermeasure to global warming. In recent years there is an increasing demand on the utilization of unused biomass instead of usual fossil oil fuel combustors for farming-greenhouses heating during the winter season. This increase in the demand will make prices to increase. In general, these combustors are small in size (Johansson et al. [5]) therefore existing regulations do not apply (e.g. the air pollution control act and the waste disposal and public cleaning law). So far, small size combustors are characterized by simplicity on their structure and low costs, however, visible black smoke and pollutants emitted due to the poor combustion performance and the lack of regulations (Simoneit [6]; Wiinikka and Gebart [7]). In this study, we investigated that waste rice husk could be used as biomass fuel based on our laboratory model combustion experiments. Firstly, we analyzed the chemical composition of agricultural waste rice husk and straw investigated its combustion characteristics. Then, the air pollutants emitted from waste rice husk and straw combustion were measured by sampling suspended particulate matter and gases in the exhaust under the different combustion conditions. The possibility of reduction of these harmful substances in $\mathrm{PM}_{2.5}$ and the exhaust gases were also investigated. 


\section{Experimental methods}

\subsection{Composition analysis of the rice husk and straw}

In this study, rice husk and straw composition (Nigata Prefecture of Japan) were analyzed. The proximate and ultimate analyses of their samples were carried out according to the Japanese industrial standard (JIS) method of JIS-M8812 and JIS-M8813.

\subsection{Evaluation method of the combustion characteristics of the rice husk and straw}

Combustion characteristics of rice husk and straw were analyzed by the thermogravimetric/differential thermal analysis (TG/DTA, Model DTG-60, Shimadzu Co. Ltd., Japan), and under the following conditions: samples were prepared below $250 \mu \mathrm{m}$ by several sieves. About $4.0 \mathrm{mg}$ of samples were heated at a rate of $5^{\circ} \mathrm{C} \mathrm{min}{ }^{-1}$ starting from room temperature until $900^{\circ} \mathrm{C}$. A gas flow rate of $250 \mathrm{~mL} \mathrm{~min}{ }^{-1}$ was used; clean gas was used as the carrier gas for combustion.

\subsection{Evaluation of suspended particulate matter (SPM) in exhaust gases}

\subsubsection{Air sampling method for method for exhaust gases collection}

Biomass burning is an important source of primary fine particles in the atmosphere, which can influence the regional air pollution and human health. Recently, fine particles below $2.5 \mu \mathrm{m}$ in aerodynamic diameter (e.g. $\mathrm{PM}_{2.5}$ ) either emitted from biomass burning or generated by photochemical reactions, are of great concern because of their effect on health and environment in Japan. For example, coarse particles of suspended particulate matter are mainly having particle sizes larger than $2 \mu \mathrm{m}$ and it unable to instruction in to entering the respiratory tract by the nose, throat, and pharynges. Therefore, in this study, evaluate the PM2.5 from combustion of waste rise husk and straw. The collection devices of exhaust gases are shown in figure 1. In order to evaluate the $\mathrm{PM}_{2.5}$ emissions for the combustor, exhaust $\mathrm{PM}_{2.5}$ were collected on quartz-fiber filters (35 mm $\varphi$, Pallflex Products Corp, 2500QAT-UP) and Teflon filters (35 mm $\varphi$, Pallflex Products Corp, T8711A) using two air samplers which are called the PM2.5 personal sampler (Model NWPS-35HS, Sibata Scientific Technology Co. Ltd., Japan). The quartz-fiber filter was used for carbonaceous and ionic composition analysis, and the Teflon filters were used for metal composition analysis. Gaseous components $\left(\mathrm{CO}, \mathrm{CO}_{2}, \mathrm{NOx}\right.$ and $\left.\mathrm{O}_{2}\right)$ were also evaluated by portable gas analyzer (Model PG-250, Horiba Co. Ltd.). 


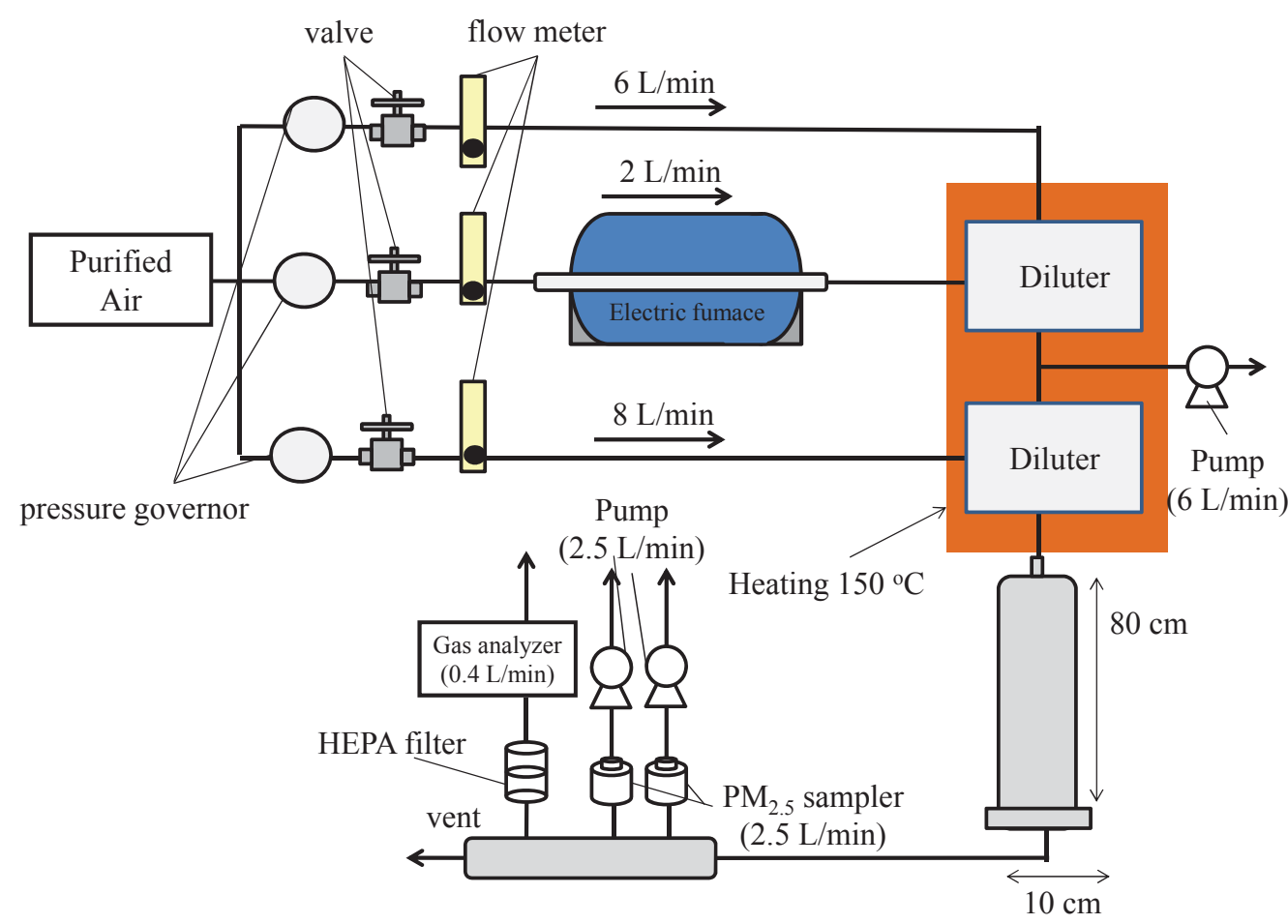

Figure 1: Air sampling setup for exhaust gases emitted from the combustor.

2.3.2 Evaluation of carbonaceous compositions of $\mathbf{P M}_{2.5}$ in the exhaust gases Carbonaceous analysis was based on the IMPROVE method (Interagency Monitoring of Protected Visual Environment) by the thermo-optical carbon analyzer (thermo/optical carbon analyzer: Model 2001, Desert Research Institute) shown in table 1 . In this method, a $0.503 \mathrm{~cm}^{2}$ ( $8 \mathrm{~mm}$ diameter $)$ punch aliquot of a sample quartz filter was heated at $120^{\circ} \mathrm{C}(\mathrm{OC} 1), 250^{\circ} \mathrm{C}(\mathrm{OC} 2)$,

Table 1: Protocol of IMPROVE thermal/optical method for carbonaceous analysis.

\begin{tabular}{ccc}
\hline \multicolumn{3}{c}{ Thermal / optical method } \\
\hline Fraction & Temperture $\left({ }^{\circ} \mathrm{C}\right)$ & Atmosphere \\
\hline OC1 & 120 & \\
OC2 & 240 & $100 \% \mathrm{He}$ \\
OC3 & 450 & \\
OC4 & 550 & \\
\hline EC1 & 550 & \\
EC2 & 700 & $2 \% \mathrm{O}_{2}+98 \% \mathrm{He}$ \\
EC3 & 800 & \\
\hline
\end{tabular}


$450^{\circ} \mathrm{C}(\mathrm{OC} 3)$, and $550^{\circ} \mathrm{C}(\mathrm{OC} 4)$ in a helium atmosphere, and then at $550^{\circ} \mathrm{C}$ (EC1), $700{ }^{\circ} \mathrm{C}(\mathrm{EC} 2)$, and $800{ }^{\circ} \mathrm{C}(\mathrm{EC} 3)$ in an oxidizing atmosphere of $2 \%$ oxygen and $98 \%$ helium. The analysis was repeated two or three times for each sample for better accuracy. PM2.5 samples were collected at the flow rate of $2.5 \mathrm{~L}$ min-1 for the combustion out on each sampling with the PM2.5 personal sampler.

\subsubsection{Evaluation of ionic composition of suspended particulate matter in the exhaust gases}

One half of the $35 \mathrm{~mm} \varphi$ quartz-filter was ultrasonically extracted with $5 \mathrm{~mL}$ ultrapure water (18.2M $\Omega$ milli-Q ultrapure water) for 20 minutes, in order to carry the ionic composition analysis. The concentrations of the following cations were measured: $\mathrm{Ca}^{2+}, \mathrm{K}^{+}, \mathrm{NH}^{4+}$, and $\mathrm{Na}^{+}$and the following anions: $\mathrm{SO}_{4}{ }^{2-}, \mathrm{NO}^{3-}$, and $\mathrm{Cl}^{-}$anions and cations were analyzed in two different ion chromatographs (IC, Model DX-100, Dionex Co. Ltd., Japan).

\section{Results and discussions}

\subsection{Measurements in the composition of waste rice husk and straw}

The bulk composition of biomass in terms of carbon, hydrogen, and oxygen $(\mathrm{CHO})$ did not differ much among different biomass sources. Typical dry weight percentages for $\mathrm{C}, \mathrm{H}$, and $\mathrm{O}$ were $30 \%$ to $60 \%, 5 \%$ to $6 \%$, and $30 \%$ to $45 \%$ respectively (Khan et al. [8]). Table 2 shows the composition analysis of waste rice husk and straw. As the results, proximate analysis, of rice husk indicated that ash contents were high in waste rice husk, while the carbon contents were low from the ultimate analysis of waste rice husk and straw. It is mean that waste rice husk heating value is low than waste rice straw. However, waste rice husk and straw is much lower when compared to fossil fuel. Therefore, it is necessary to find the suitable combustion conditions for effective utilization as biomass fuel of waste rice husk and straw.

Table 2: $\quad$ Rice husk and straw composition analysis.

\begin{tabular}{|c|c|c|c|c|c|c|c|c|}
\hline \multirow{2}{*}{ Sample } & \multicolumn{4}{|c|}{ Proximate analysis (wt $\%)$} & \multicolumn{4}{|c|}{ Ultimate analys is (wt\%) } \\
\hline & M & $\mathrm{VM}$ & Ash & $\mathrm{FC}$ & $\mathrm{C}$ & $\mathrm{H}$ & $\mathrm{N}$ & $\mathrm{O}$ \\
\hline Rice hus & 5.4 & 62.5 & 17.5 & 14.6 & 45.11 & 5.87 & 0.52 & 30.99 \\
\hline Rice straw & 5.3 & 69.2 & 9.2 & 16.3 & 39.19 & 5.26 & 0.51 & 45.89 \\
\hline
\end{tabular}

$\mathrm{M}:$ Moisture, VM : Volatile matter and FC : Fixed carbon

\subsection{Differential combustion characteristics of the rice husk types}

Rice husk and rice straw was observed a similar trend in case of TG/DTA (figure 2). The TG/DTA thermogram for rice husk showed two well-defined peaks at $280^{\circ} \mathrm{C}$ and around $400^{\circ} \mathrm{C}$. These results show that waste rice husk 
achieves its pyrolysis around $280^{\circ} \mathrm{C}$, where the more volatile components were burned while the carbonized fraction was burned at a higher temperature, around $400^{\circ} \mathrm{C}$. For this reason, the waste rice husk can only be combusted under the conditions of the temperatures above $500^{\circ} \mathrm{C}$. In this study, combustion temperature was carried out in each $100^{\circ} \mathrm{C}$ between 500 and $1000^{\circ} \mathrm{C}$.

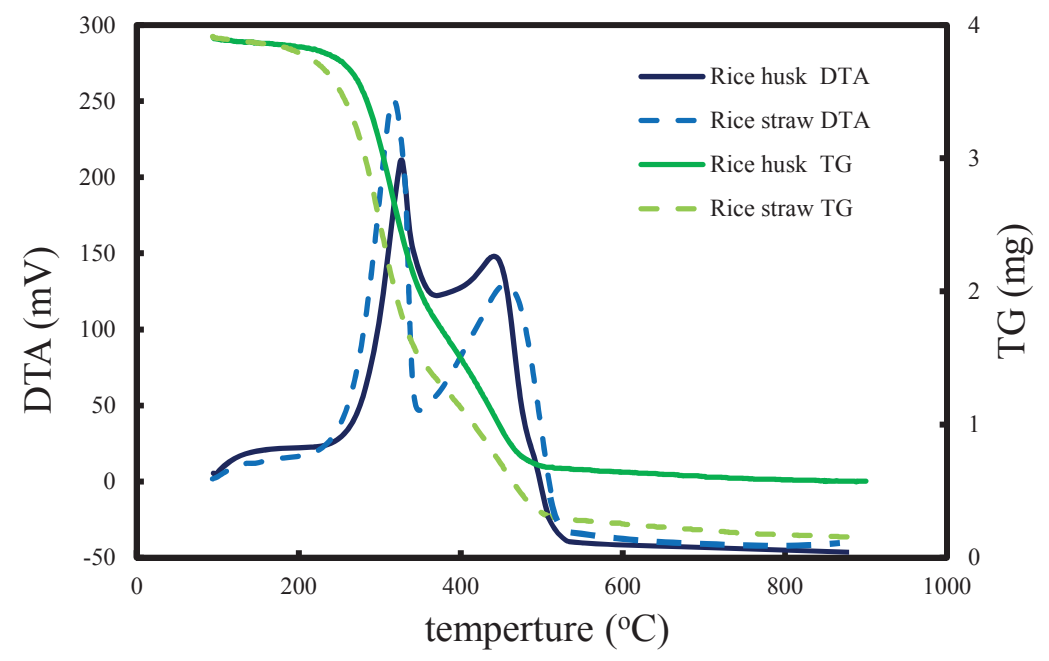

Figure 2: $\quad$ Pyrolysis and combustion behavior of rice husk and rice straw.

\subsection{Air pollutant emitted from combustion of waste rice husk under the different combustion temperatures}

\subsubsection{Gases components and combustion efficiencies}

In this study, to simplify the combustion efficiency, we used the fact that $>90 \%$ of the carbon combusted in a fire was emitted in the form of $\mathrm{CO}_{2}$ and $\mathrm{CO}$, and $<10 \%$ of carbon was in species such as hydrocarbons and particulate carbon. With this in mind, the modified combustion efficiency (MCE) can be defined as the equation (1). According to the $\mathrm{MCE}$, the combustion conditions can be categorized, when $\mathrm{MCE} \geqq 0.9$ indicates smoldering combustion and $\mathrm{MCE}<0.9$ indicates flaming combustion (Ward and Hao [9]).

$$
\mathrm{MCE}=\frac{[\mathrm{C}]_{\mathrm{CO}_{2}}}{[\mathrm{C}]_{\mathrm{CO}}+[\mathrm{C}]_{\mathrm{CO}_{2}}}
$$

The behavior of gaseous components during waste rice husk and straw combustion under different temperatures $\left(500-1000^{\circ} \mathrm{C}\right)$ is shown in figure 3 . It was found that all of gas concentrations showed the similar behavior in two temperature ranges $500-700^{\circ} \mathrm{C}$ and $800-1000^{\circ} \mathrm{C}$.

Figure 4 shows the variation of the modified combustion efficiency (MCE) under all combustion conditions with the different temperatures. For example, as figure 3 also shows, during the temperature ranges of $700-800^{\circ} \mathrm{C}, \mathrm{CO}$ and $\mathrm{O}_{2}$ concentrations were increased under smoldering combustion conditions, and 

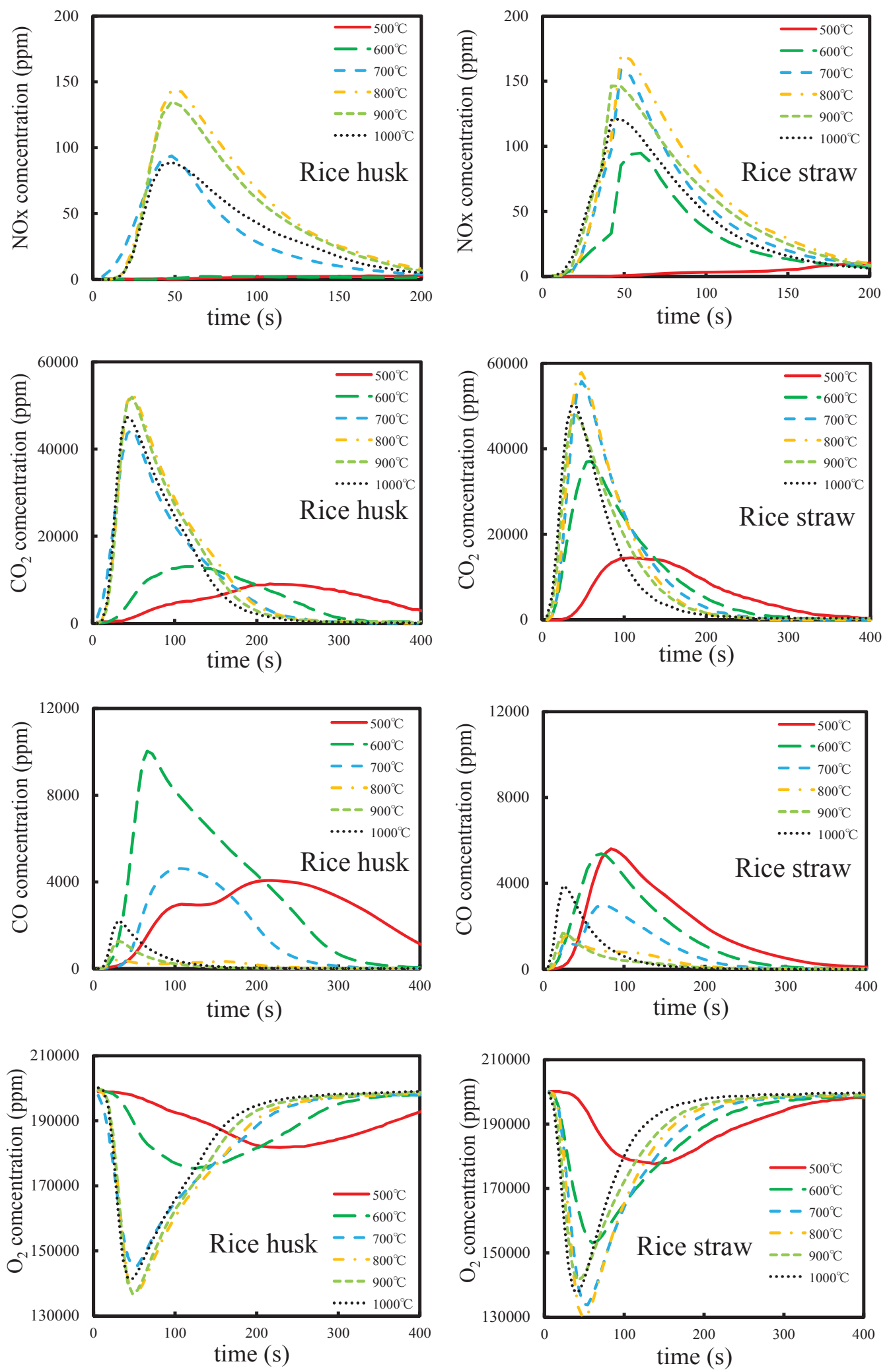

Figure 3: Gas components emitted from combustion of waste rice husk and straw under the different combustion temperatures. 
$\mathrm{NO}_{\mathrm{X}}$ and $\mathrm{CO}_{2}$ concentrations were increased under flaming combustion conditions. These results indicate that the combustion efficiencies under flaming combustion are better than under smoldering combustion. Biomass fuel is regarded as a renewable energy source with low $\mathrm{CO}_{2}$ emissions if produced in a sustainable manner. Under this point of view, if we use waste rice husk and straw as more effective fuel combustion, the emission of $\mathrm{CO}_{2}$ is less or not contributing to global warning.
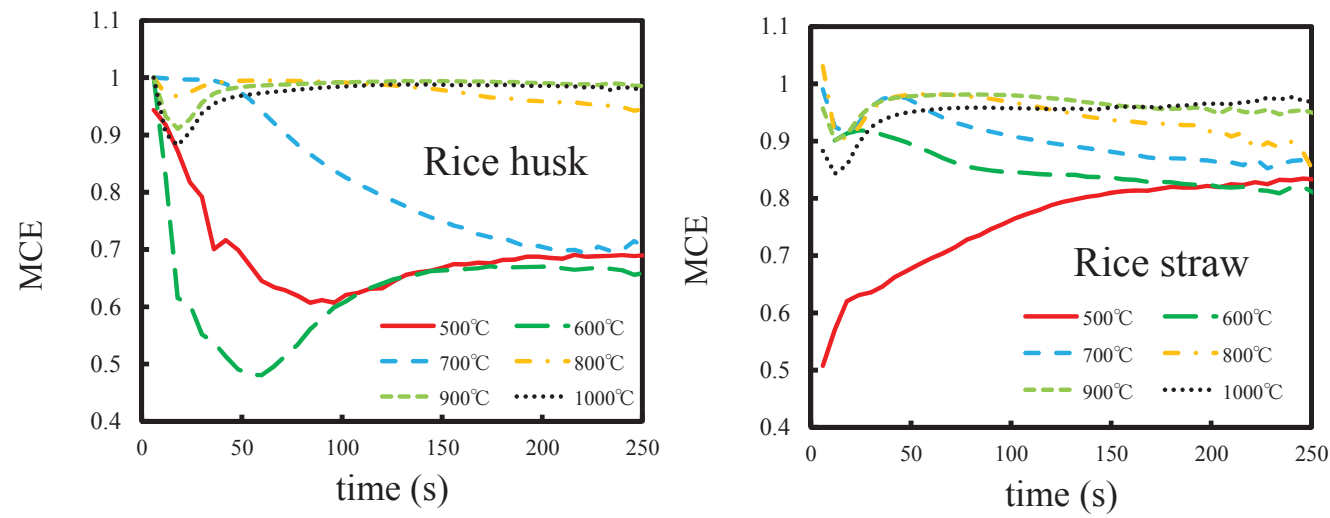

Figure 4: Gas components emitted from combustion of waste rice husk and straw under the different combustion temperatures.

\subsubsection{Cabonaceous compositions in $\mathbf{P M}_{2.5}$}

The effect of combustion temperature on carbonaceous composition in PM2.5 was investigated. The results of carbonaceous composition analysis are shown in figure 5. OC compositions includes compounds like levoglucosan and
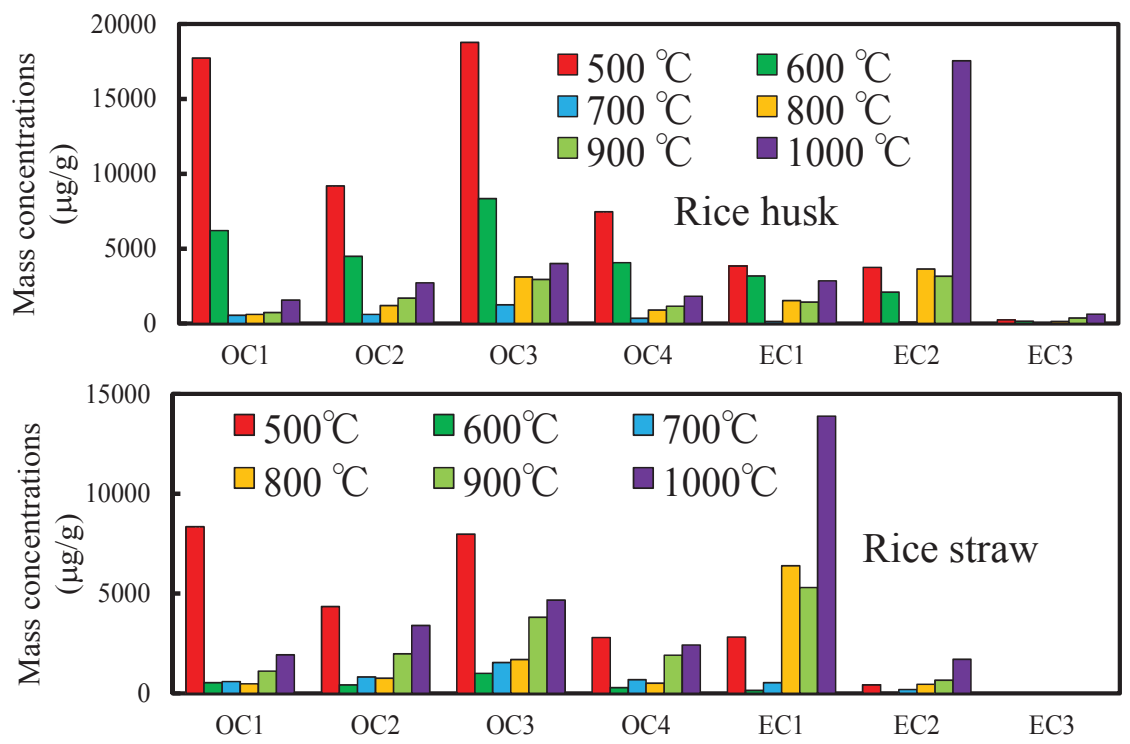

Figure 5: Carbonaceous components in $\mathrm{PM}_{2.5}$ from combustion rice husk and straw at different combustion temperature. 
methoxyphenol (Kuo et al. [10]), which are generated in the thermolysis of cellulose and lignin, levoglucosan is one of the water-soluble organic substances and it can contribute to cloud condensation nuclei and influence the optical properties of aerosol. In our results, $\mathrm{OC} 1$ was found the highest concentrations in smoldering combustion which is mainly generated by biomass combustion at low temperatures $\left(500^{\circ} \mathrm{C}\right)$. On the other hand, in smoldering combustion EC composition was dominated by EC1 (char-EC). Under flaming combustion, OC mass concentrations were decreased significantly, and EC concentrations were dominated by EC2 (soot-EC). However, EC (EC1+EC2) were emitted by smoldering combustion. Here, EC is a mostly POC, POC is OC (OC3). Therefore, as shown in figure 5, EC has not been nearly exhausted in smoldering combustion. From the results of total carbonaceous concentration $(\mathrm{OC}+\mathrm{EC})$, we observed the carbonaceous concentrations in $\mathrm{PM}_{2.5}$ under flaming combustion were 10 times lower than under smoldering combustion.

\subsubsection{Ionic compositions in $\mathbf{P M}_{2.5}$}

Ionic concentrations in $\mathrm{PM}_{2.5}$ were almost unchanged by Combustion temperature. The results are shown in figure 6 . The high concentrations of $\mathrm{SO}_{4}{ }^{2-}$ in $\mathrm{PM}_{2.5}$ were determined at all combustion temperatures. In general, $\mathrm{K}^{+}$is an important component of biomass (Jones et al. [11]), since it is used in metabolic processes; therefore, this component can be used as a marker for biomass combustion contributing to air pollution. However, in our results, $\mathrm{K}^{+}$ concentrations were low at all combustion temperature.
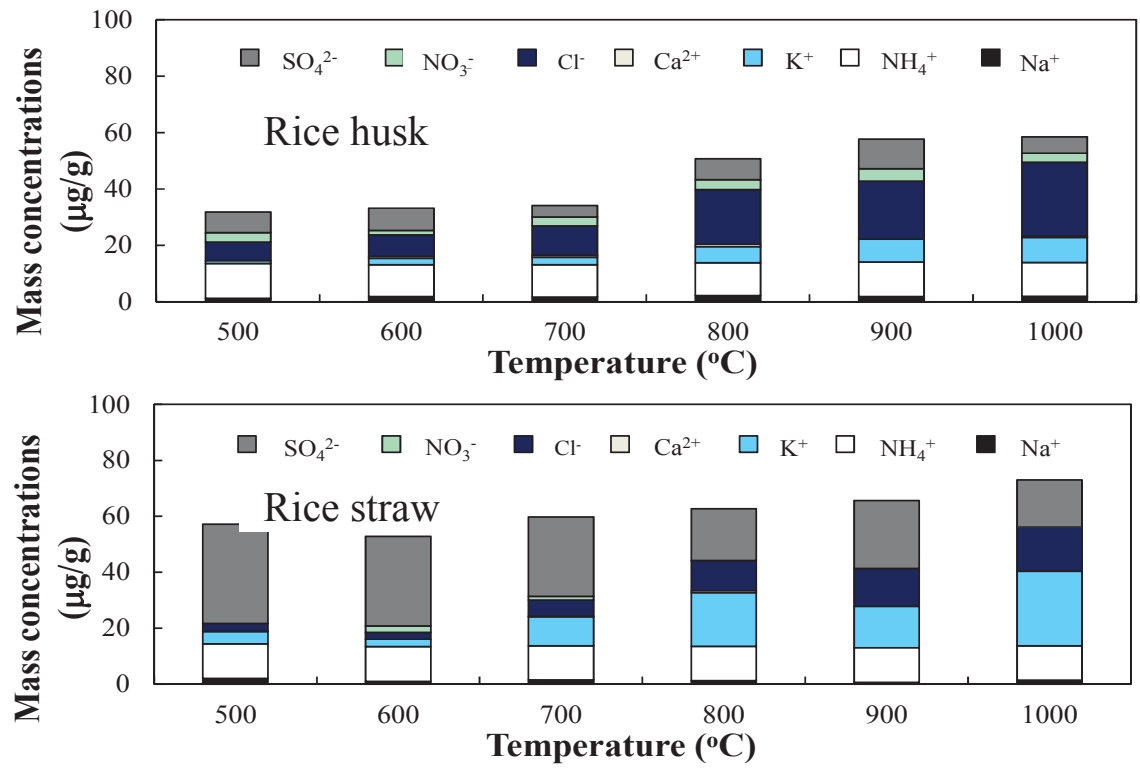

Figure 6: Ions components in $\mathrm{PM}_{2.5}$ from combustion rice husk and straw at different combustion temperature.

As mentioned above, we investigated the behavior of harmful air pollutants emitted from rice husk and straw combustion by measuring carbonaceous and ionic composition of suspended particulate matter in $\mathrm{PM}_{2.5}$ and the exhaust 
gases. We will feel glad if this information of our study is useful in production and application of small size combustors for waste rice husk or other biomass fuels. For further study, we also need to analyze for polycyclic aromatic hydrocarbons (PAHs) emitted from rice husk and straw combustion in order to effectively reduce harmful air pollutants.

\section{Conclusion}

In this study, we evaluated the possibility of waste rice husk and straw substitute fossil fuel based on laboratory model combustion experiments. According to the combustion characteristics of rice husk and straw, it is possible to use as a biomass fuel if rice husk is combusted at the temperatures above $500^{\circ} \mathrm{C}$. From analysis of gaseous compositions, it is indicated that flaming combustion (800 $1000^{\circ} \mathrm{C}$ ) showed better in its efficiency than smoldering combustion (500 $\left.700^{\circ} \mathrm{C}\right)$.

From the results of carbonaceous compositions, it was found that tenth part of carbonaceous particulate matter with smaller particle sizes may be only emitted under flaming combustion than under smoldering combustion. It can be suggested that air pollutants can be easily reduced if we can ensure stable combustion performance under suitable conditions especially for developing small size combustors.

\section{Acknowledgement}

Some parts of this study were supported by the special funds for Basic Researches (B) (No. 22404022, FY2010-2012) of Grant-in-Aid for Scientific Research of the Japanese Ministry of Education, Culture, Sports, Science and Technology (MEXT), Japan.

\section{References}

[1] R. Saidur, E.A. Abdelaziza, A. Demirbasb, M.S. Hossaina and S. Mekhilef, A review on biomass as a fuel for boilers, Renewable and Sustainable Energy Reviews, 15, 2262-2289, 2011.

[2] Li Dong, Shiqiu Gao and Guangwen Xu, No reduction over Biomass Char in the Combustion Process., Energy Fuels, 24, 446-450, 2010.

[3] Hansen, Lone A., Hanne, P. Nielsen, Flemming J. Frandsen, Kim DamJohansen, Steffen Horlyck and Asger Karlsson., Influence of deposit formation on corrosion at a straw-fired boiler., Fuel Processing Technology, 64, 189-209, 2000.

[4] E. F. Iliopoulou, E. V. Antonakou, S. A. Karakoulia, I. A. Vasalos, A. A. Lappas, and K.S. Triantafyllidis, Catalytic conversion of biomass pyrolysis products by mesoporous materials: Effect of steam stability and acidity of Al-MCM-41 catalysts, Chemical Engineering Journal, 134, 51-57, 2007. 
[5] L. S. Johansson, C. Tullin, B. Leckner and P. Sjovall, Particle emissions from biomass combustion in small combustors, Biomass and Bioenergy, 25, 435-446, 2003.

[6] Bernd R.T. Simoneit, Biomass burning-a review of organic tracers for smoke from incomplete combustion, Applied Geochemistry, 17, 129-162, 2002.

[7] Henrik Wiinikka and Rikard Gebart, Experimental investigation of the particle emissions from a small-scale pellets combustor, Biomass and Bioenergy, 27, 645-652, 2004.

[8] A. A Khan, W. de Jong, P. J. Jansens and H. Spliethoff, Biomass combustion in fluidized bed boilers: Potential problems and remedies, Fuel processing technology, 90, 21-50, 2009.

[9] Ward D. E and Hao W. M., Air toxic emissions from burning of biomass globally-preliminary estimates, Proceedings of Air \& Waste Management Assoc. 85th Annual Meeting \& Exhibition, 1992.

[10] Li-Jung Kuo, Patrick Louchouarn and Bruce E. Herbert, Influence of combustion conditions on yields of solvent-extractable anhydrosugars and lignin phenols in chars: Implications for characterizations of biomass combustion residues, Chemosphere, 85, 797-805, 2011.

[11] J. M. Jones, L. I. Darvell, T. G. Bridgeman, M. Pourkashanian and A. Williams, An investigation of the thermal and catalytic behavior of potassium in biomass combustion., Proceedings of the Combustion Institute, 31, 1955-1963, 2007. 